\title{
Inhibition of ERG Activity in Patient-derived Prostate Cancer Xenografts by YK-4-279
}

\author{
BRIAN WINTERS ${ }^{1}$, LISHA BROWN ${ }^{1}$, ILSA COLEMAN $^{2}$, HOLLY NGUYEN $^{1}$, \\ TSION ZEWDU MINAS ${ }^{3}$, LORI KOLLATH ${ }^{1}$, VALERI VASIOUKHIN ${ }^{2}$, \\ PETER NELSON ${ }^{2}$, EVA COREY $^{1}$, AYKUT ÜREN $^{3}$ and COLM MORRISSEY ${ }^{1}$ \\ ${ }^{1}$ Department of Urology, University of Washington, Seattle, WA, U.S.A.; \\ ${ }^{2}$ Fred Hutchinson Cancer Research Center, Seattle, WA, U.S.A.; \\ ${ }^{3}$ Department of Oncology Department of Biochemistry and Molecular \& Cellular Biology, \\ Georgetown University Medical Center, Lombardi Comprehensive Cancer Center, Washington, DC, U.S.A.
}

\begin{abstract}
Background/Aim: The aim of the current study was to determine the effects of the ERG small-molecule inhibitor $Y K$ 4-279 on ERG ${ }^{+}$prostate cancer patient-derived xenografts (PDX). Materials and Methods: ERG activity was blocked using $Y K-4-279$ in three subcutaneously-implanted $E R G^{+}$(LuCaP 23.1, 86.2 and 35) and one $E R G^{-}$(LuCaP 96) PDX. Treated animals tumor volume $(T V)$, body weight $(B W)$ and serum prostate-specific antigen (PSA) were compared to vehicle-treated control animals. Gene expression, proliferation, apoptosis, microvessel density and ERG expression were also assessed. Results: Administration of YK-4-279 decreased TV $(p=0.026)$, proliferation $(p=0.0038)$ and PSA $(p=0.022)$ in Severe Combined Immunodeficiency (SCID) mice bearing LuCaP 23.1 tumors. LuCaP 86.2, LuCaP 35 and LuCaP 96 showed no significant changes in TV, or PSA. Mineralocorticoid receptor $(M R)$ and MR-direct target genes were up-regulated in treatment-resistant $\mathrm{LuCaP} 86.2$ and $L u C a P 35$ PDX. Conclusion: YK-4-279 decreased ERG ${ }^{+} L u C a P 23.1$ tumor growth, but not $\mathrm{LuCaP} 86.2$ and $\mathrm{LuCaP} 35 \mathrm{ERG} G^{+}$tumor growth.
\end{abstract}

Prostate cancer $(\mathrm{PCa})$ remains a heterogeneous disease with multiple genetic (1) and epigenetic (2) factors. In 2005, Tomlins et al. discovered the TMPRSS2-ERG gene fusion, a combination of a prostate-specific, androgen-responsive, transmembrane serine protease and the 'ETS related gene' or ERG (1). ERG expression is normally present in endothelial

This article is freely accessible online.

Correspondence to: Colm Morrissey, Ph.D., Department of Urology, Genitourinary Cancer Research Laboratory, Box 356510 , University of Washington, Seattle, WA 98195, U.S.A. Tel: +1 2065431461, Fax: +1 2065431146, e-mail: cmorriss@uw.edu

Key Words: Prostate cancer, ERG, xenografts, YK-4-279. and hematopoietic cell lines (3), however when fused with TMPRSS2, ERG proteins are aberrantly transcribed, resulting in downstream activation of ERG target genes resulting in cellular proliferation (4).

Clinically, the TMPRSS2-ERG fusion is found in $40-50 \%$ of primary $\mathrm{PCa}(5,6)$ with slightly less prevalence in $\mathrm{PCa}$ metastases $(25-40 \%)(7,8)$. There have been mixed results, thus far, when discussing the clinical and prognostic implications of TMPRSS2-ERG with some studies indicating aggressive disease $(9,10)$, while other studies suggest more benign associations $(11,12)$. Furthermore, there is some evidence that the relative level of ERG expression carries prognostic significance with one study describing higher expression levels as predictive of more advanced disease (13).

In 2009, Erkizan and colleagues studied a similar translocation-generated fusion protein in Ewing's Sarcoma, EWS-FLI1 (14). Through direct binding screening, they discovered the small-molecule inhibitor, YK-4-279. Subsequent experiments revealed increased apoptosis and decreased xenograft tumor growth in YK-4-279-treated EWS-FLI1 ${ }^{+}$lines (14). As FLI1 is a class I ETS gene with homology to ERG and ETV1, this molecule was then tested in several PCa lines with initial studies of $\mathrm{LNCaP}\left(\mathrm{ETV}^{+}\right)$and $\mathrm{VCaP}\left(\mathrm{ERG}^{+}\right)$showing decreased transcriptional activity, downstream protein expression and reduced invasive capacity (15). Further experiments with ETV1 xenograft models revealed YK-4-279 treatment reduced tumor growth and metastases relative to control while expression of downstream ETV1 target genes were inhibited (16).

We chose to study YK-4-279 in pre-clinical PDX models to evaluate the translational application of ERG inhibitors in $\mathrm{ERG}^{+}$PCa patients. YK-4-279 inhibition of $\mathrm{ERG}^{+} \mathrm{PDX}$ revealed significant tumor volume, proliferation and prostate specific antigen (PSA) response in one line ( $\mathrm{LuCaP} 23.1)$, partial response in another ( $\mathrm{LuCaP} 86.2)$, with no response in the third $\mathrm{ERG}^{+} \mathrm{PDX}(\mathrm{LuCaP} 35)$ and the $\mathrm{ERG}^{-}$control (LuCaP 96). Overall survival was not significantly improved 
Table I. Primer sequences for qPCR analysis.

\begin{tabular}{lll}
\hline Primer name & Primer sequence & Probe sequence \\
\hline ERG forward & 5'AGGCCAGATTTACCATATGAGC 3' & CAGCCTGG \\
ERG reverse & 5'GGAGATGGTTGAGCAGCTTT 3' & TGCTGGAG \\
RPS16 forward & 5'CGCGCACGCTACAGTACA 3' & \\
RPS16 reverse & 5'CGGATGTCTACACCAGCAAA 3' \\
\hline
\end{tabular}

in any of the animals bearing $\mathrm{ERG}^{+}$PDXs. Molecular analysis suggested that ERG inhibition resulted in an increase in mineralocorticoid receptor (MR) and downstream associated gene expression in the two $\mathrm{ERG}^{+} \mathrm{PDX}$ lines that were treatment resistant.

\section{Materials and Methods}

LuCaP PDX. Human PCa specimens were obtained as part of the University of Washington Medical Center Prostate Cancer Donor Program, which is approved by the University of Washington Institutional Review Board. All animal studies described in this article were approved by and performed in compliance with the University of Washington Institutional Animal Care and Use Committee and $\mathrm{NIH}$ guidelines. The LuCaP PDX lines were maintained by serial passage in severe combined immunodeficient (SCID) male mice. All LuCaP xenograft lines were evaluated for ERG expression by quantitative PCR (qPCR) and immunohistochemistry (IHC) (Figure 1). We utilized four Lucas Foundation Cancer of the Prostate (LuCaP) PDX models including three $\mathrm{ERG}^{+}$and one $\mathrm{ERG}^{-}$as control. $\mathrm{ERG}^{+}$ LuCaP lines 23.1 and 35 were derived from metastatic lymph nodes, while 86.2 was derived from a bladder metastasis. ERG- LuCaP $96^{-1}$ (control) was derived from a transurethral resection of the prostate (TURP) specimen.

Quantitative PCR. qPCR was performed on Prism 7900HT (Applied Biosystems, Foster City, CA, USA) with Platinum qPCR SupermixUDG with ROX (Life Technologies, Carlsbad, CA, USA). RT-qPCR assays and conditions were designed and performed as recommended by the Universal ProbeLibrary Assay Design Center (Roche, Basel, Switzerland). Probes used for the detection of ERG and RPS16 are listed in Table I. qPCR data were normalized to RPS 16.

Animal study design. CB-17 SCID mice (Charles River) were implanted subcutaneously with either LuCaP 23.1, 86.2, 35, or 96 tumor tissue. Animals underwent rolling enrollment once tumors reached $100 \mathrm{~mm}^{3}$ and were randomized into one of two groups (Control vs. Treatment). Group 1 (Control) received vehicle (37.5 $\mu \mathrm{L}$ DMSO/12.5 $\mu \mathrm{L} \mathrm{PBS)} \mathrm{via} \mathrm{intraperitoneal} \mathrm{injection} \mathrm{while} \mathrm{Group} 2$ (Treatment) received YK-4-279 (150 mg/kg) in $37.5 \mu \mathrm{L}$ DMSO/12.5 $\mu \mathrm{L}$ PBS as per Rahim et al. (16). All animals were dosed thrice weekly with dosing continued until tumors reached $1000 \mathrm{~mm}^{3}$. Tumor volumes (TV) were measured using digital calipers (calculated as $\mathrm{L} \times \mathrm{H} \times \mathrm{W} \times 0.5236)$ and body weights $(\mathrm{BW})$ were measured twice weekly. Serum PSA was measured weekly until euthanasia using an ARCHITECT Chemiluminescent Microparticle Total PSA assay
(Abbot Laboratories, Chicago, IL, USA). Animals were euthanized after up to 10 weeks of follow up, when tumors exceeded $1,000 \mathrm{~mm}^{3}$, or when animals became otherwise compromised. The tumors were then divided equally into paraffin blocks with the remainder flash frozen for subsequent sequencing analysis.

RNA sequencing. Flash frozen $\mathrm{LuCaP}$ PCa xenograft tissue samples were histologically evaluated for regions of viable tumor. RNA was isolated from 16 xenografts of animals ( 2 control, 2 treated from each line) with $\geq 80 \%$ tumor content. For xenografts with $<80 \%$ tumor, stroma and necrotic tissue were removed prior to sectioning. RNA was extracted using the Qiagen RNeasy Kit, (Qiagen Inc., Valencia, CA, USA), according to the manufacturer's protocol. Oncolumn DNase digestion was performed. RNA concentration, purity and integrity were assessed by NanoDrop (Thermo Fisher Scientific Inc., Waltham, MA, USA) and Agilent Bioanalyzer. RNA-Seq libraries were constructed from $1 \mu \mathrm{g}$ total RNA using the Illumina TruSeq Stranded mRNA LT Sample Prep Kit according to the manufacturer's protocol. Barcoded libraries were pooled and sequenced six per lane on the Illumina HiSeq 2500 generating $50 \mathrm{bp}$ paired end reads. Sequencing reads were mapped to the hg 19 human and $\mathrm{mm} 9$ mouse genomes using TopHat v2.0.12. Sequences aligning to the mouse genome deriving from potential contamination with mouse tissue were removed from the analysis as previously described (17). Gene level abundance was quantitated from the filtered human alignments in $\mathrm{R}$ using the Genomic Alignments Bioconductor package v1.0.1. Differential expression was assessed using transcript abundances as inputs to the edgeR Bioconductor package in R. For edgeR analysis, genes filtered for a minimum expression level of at least 1 count per million reads (CPM) in at least two samples were used to calculate expression differences using an exact test with a negative binomial distribution, applying a significance level of 0.05 with Benjamin-Hochberg false discovery rate (FDR) adjustment (GEO accession \# GSE86387).

Tissue microarray construction. Each tumor was fixed in buffered formalin and embedded in paraffin. Xenograft tissue microarrays (TMAs) were constructed using duplicate 1-mm diameter cores from 70 control and 71 treated tumors.

Immunohistochemistry. Five-micron thick sections of the TMAs were deparaffinized and rehydrated in sequential xylene and graded ethanol. Antigen retrieval was performed in $10 \mathrm{mM}$ citrate buffer (pH 6.0) in a pressure cooker. Endogenous peroxidase and avidin/biotin were blocked respectively (Vector Laboratories Inc., Burlingame, CA USA). Sections were then incubated with 5\% normal goat-horse-chicken serum, incubated with primary antibody 

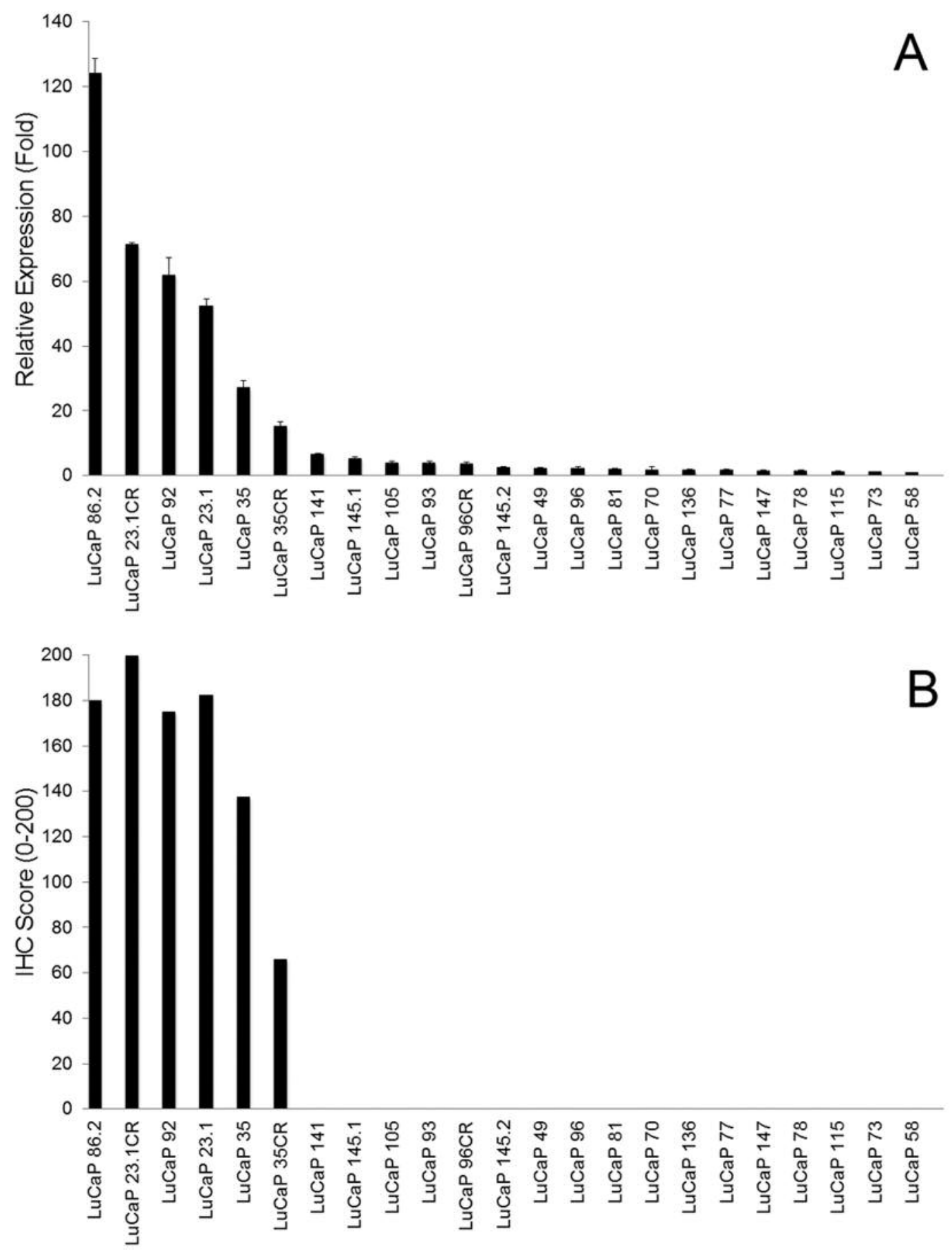

Figure 1. Expression of ERG transcript and protein in LuCaP Xenograft lines: Of the twenty-three LuCaP PDX models assayed by qPCR analysis, six models (LuCaP 23.1 and $23.1 \mathrm{CR}, \mathrm{LuCaP} 35$ and $35 \mathrm{CR}, \mathrm{LuCaP} 86.2$ and LuCaP 92.1) expressed ERG at the transcript (A) and protein (B) levels. $C R=$ Castrate Resistant. ERG transcript levels are expressed relative to RPS16.

(Table II), incubated with biotinylated secondary antibody (Vector Laboratories Inc., Burlingame, CA, USA), followed by ABC reagent (Vector Laboratories Inc., Burlingame, CA, USA) and stable DAB (Invitrogen Corp., Carlsbad, CA, USA). All sections were counterstained with hematoxylin and mounted with Cytoseal XYL (Richard Allan Scientific, San Diego, CA, USA). Mouse or rabbit IgG (Vector Laboratories Inc., Burlingame, CA, USA) were used as negative controls. 

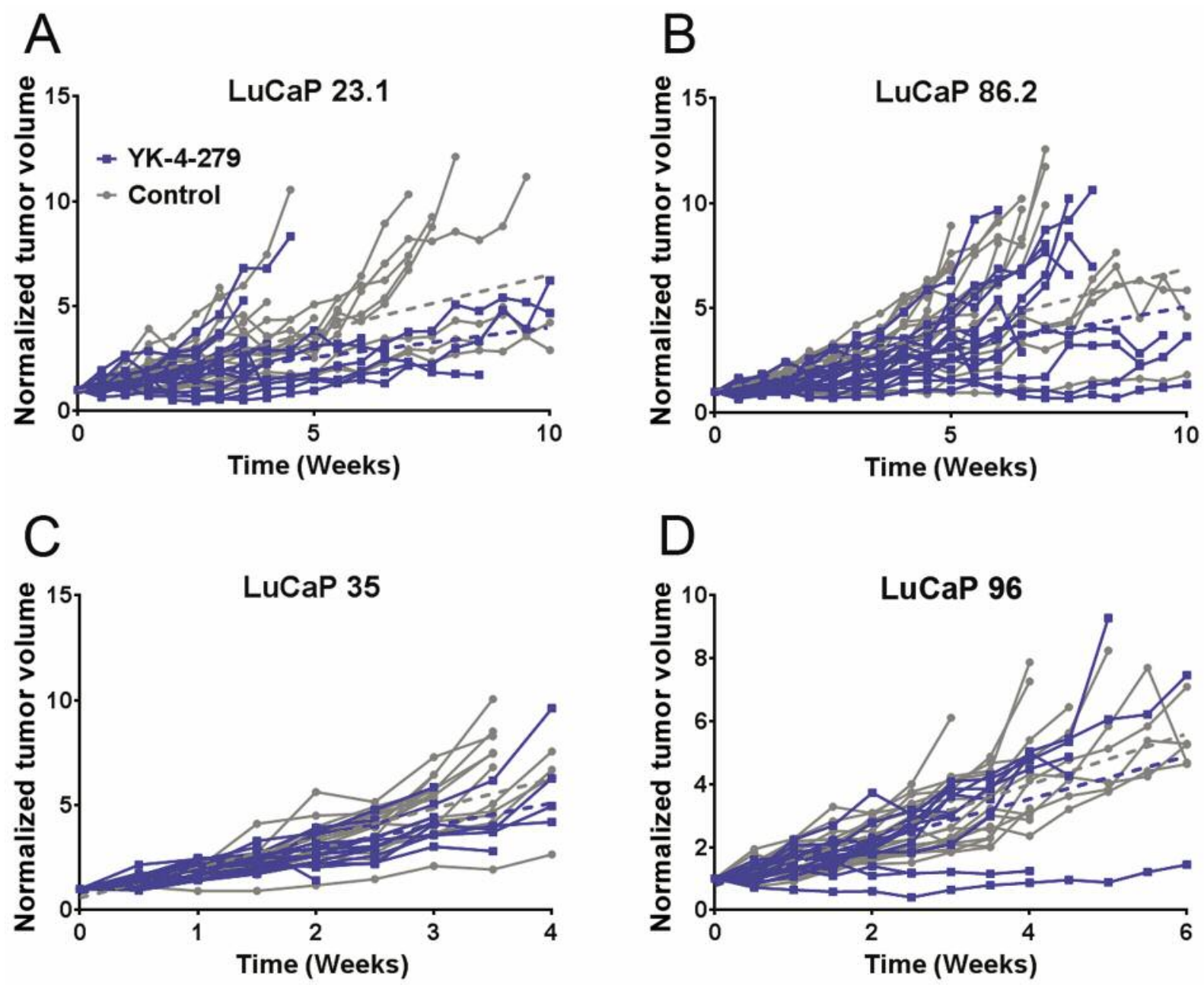

Figure 2. Tumor volume in YK-4-279-treated ERG ${ }^{+}$LuCaP 23.1, 35 and 86.2 and ERG- LuCaP 96: LuCaP 23.1 animals treated with YK-4-279 $(n=18)$ had significantly decreased normalized tumor volume $(T V)(p=0.026)$ compared to controls $(n=18)(A)$. LuCaP 86.2 treated animals $(n=17)$ showed a trend towards decreased normalized TV $(p=0.056)$ compared to controls $(n=17)(B)$. LuCaP 35 treated animals $(n=17)$ revealed no overall trends in normalized TV ( $p=0.649)$, compared to control animals $(n=17)(C)$. LuCaP 96 treated animals $(n=19)$ revealed no overall trends in normalized TV $(p=0.533)$ compared to controls $(n=18)(D)$. Individual TVs are plotted. Blue $=Y K-4-279$ treated vs. Grey=untreated animals.

Immunohistochemical assessment. Proliferation was assessed by determining the mitotic index counting up to 3 fields/ core for duplicate $1 \mathrm{~mm}$ punches at 200x magnification (two observers, $\mathrm{CM}$ and LB). Microvessel density was assessed using CD34 (Table II). Duplicate $1 \mathrm{~mm}$ punches were visualized and Ki-67+ tumor cells or $\mathrm{CD} 34^{+}$endothelial cells were counted relative to negative controls. Averages were computed followed by overall averages for treated and untreated tumors and expressed as a ratio. ERG immunostaining was assessed using a quasi-continuous scoring system, created by multiplying each optical density level ("0" for no brown color, "1" for faint and fine brown chromogen deposition, and " 2 " for clear and coarse granular chromogen clumps) by the percentage of cells at each staining level. The sum of the 3 multiplicands provided a score for each tissue core (score range: 0-200). The final score for each sample was the average of 2 duplicated tissue cores. Only nuclear positivity was evaluated in ERG IHC staining. The final scores were categorized as "none" (score range: 0), "weak" (score range: 1-100), "moderate" (score range: 101-150) and "intense" (score range: 151-200). Unusable samples, including missing, necrotic or folded tissue cores, were excluded from final analysis.

Statistical analysis. Tumor volume (TV), prostate specific antigen (PSA), body weight (BW) and overall survival (OS) between control and treated animals were compared when $>2$ animals remained in each group. Prior to analysis, Grubb's outlier test was performed on TV, PSA and BW with signifcant values $(p<0.05)$ excluded. Differences in TV, PSA and BW between control and treated animals were calculated using unpaired $t$-tests with unequal variances, with significance set at $p \leq 0.05$. Kaplan-Meier analysis was performed for overall survival using the log-rank (Mantel-Cox) test. For IHC comparison, unpaired $t$-tests with unequal variances and significance set at $p \leq 0.05$ were utilized. 

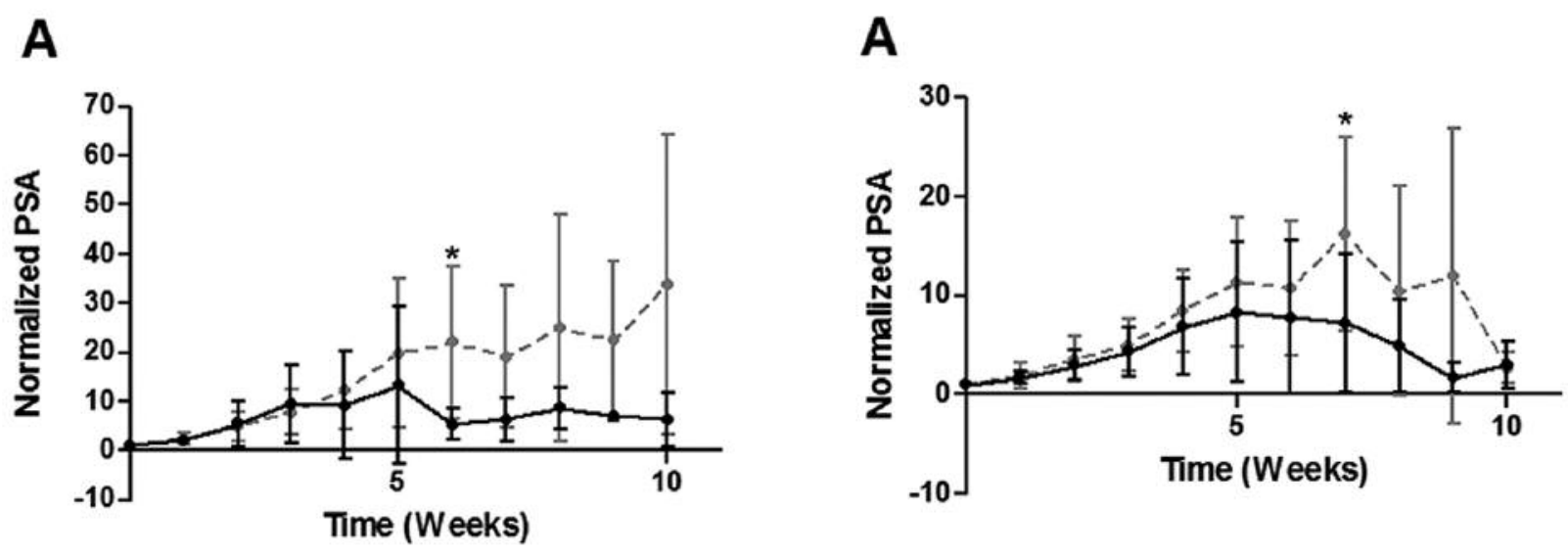

B

\section{B}
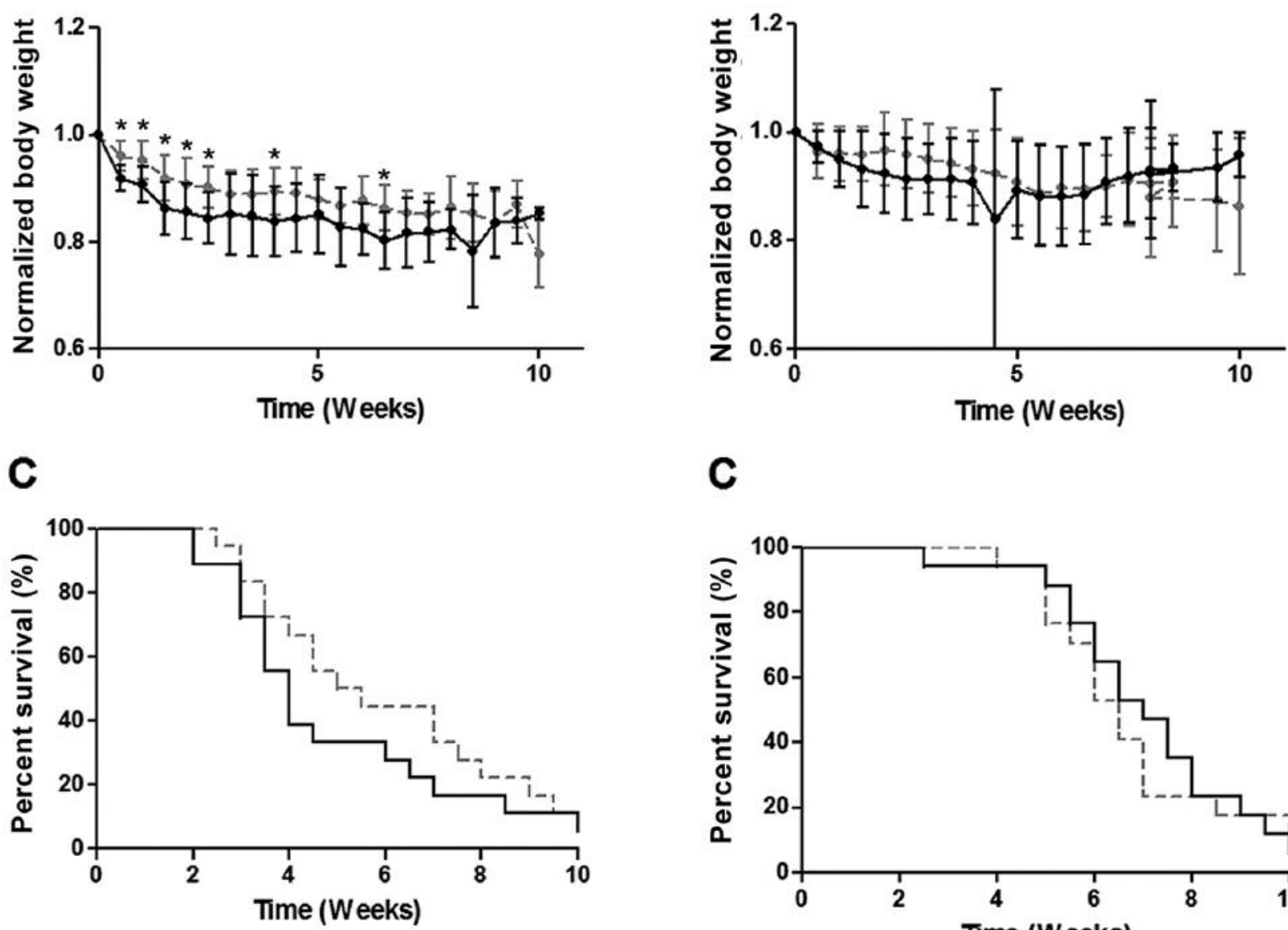

Figure 3. YK-4-279 Treatment of ERG ${ }^{+}$LuCaP 23.1. LuCaP Animals treated with YK-4-279 $(n=18)$ experienced significantly decreased normalized serum PSA values (A) $(p=0.023)$ compared to controls $(n=18)$. Normalized body weight was also significantly decreased in these animals $(B)(p=0.018)$, but no effect on overall survival was seen $(C),(p=0.440)$. PSA and BW results are plotted as normalized mean $\pm S E M$. $p$-Values pertain to overall treated vs. untreated animals. Individual data points marked with * indicate significant difference between control and treated animals at that time point. Gray hatched line $=$ vehicle control, continous black line: YK-4-279 treated .

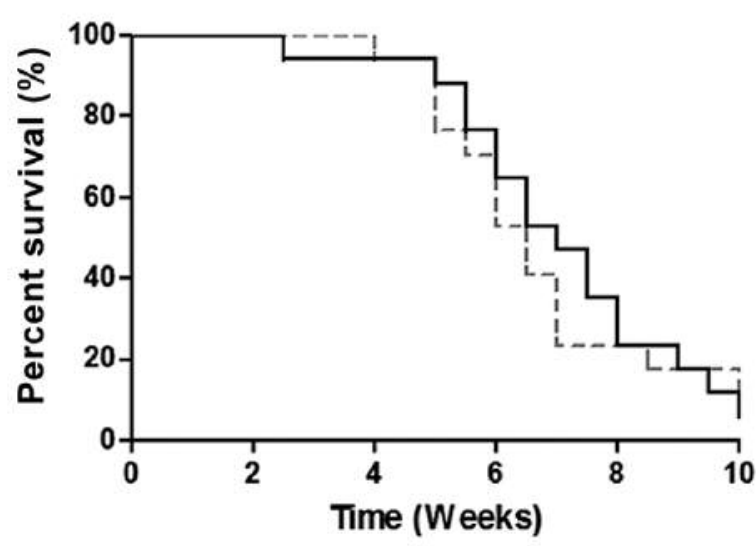

Figure 4. YK-4-279 Treatment of ERG ${ }^{+}$LuCaP 86.2. LuCaP 86.2 treated animals $(n=17)$ showed a trend towards decreased normalized serum PSA (A) ( $p=0.092)$ compared to controls $(n=17)$. There were no differences in normalized $B W(B)(p=0.762)$ or $O S(C)(p=0.763)$ seen. $P S A$ and $B W$ results are plotted as normalized mean \pm SEM. $p$-Values pertain to overall treated vs. untreated animals. Individual data points marked with * indicate significant difference between control and treated animals at that time point. Gray hatched line=vehicle control, continous black line: YK-4-279 treated. 
A

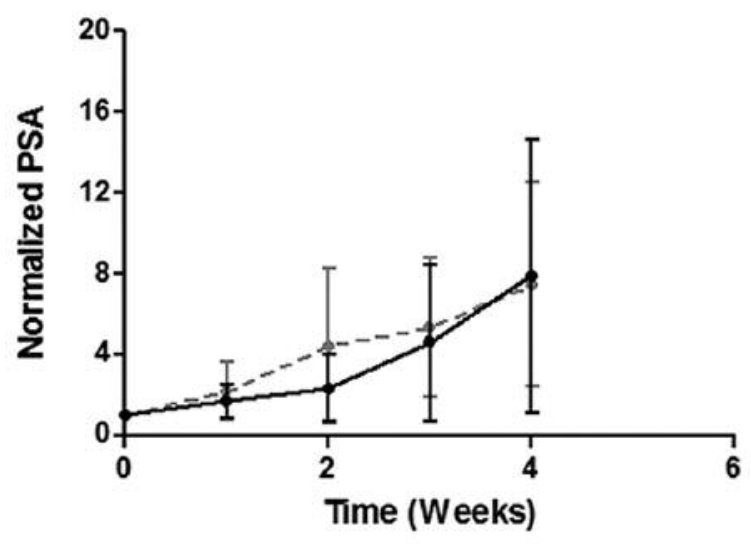

B

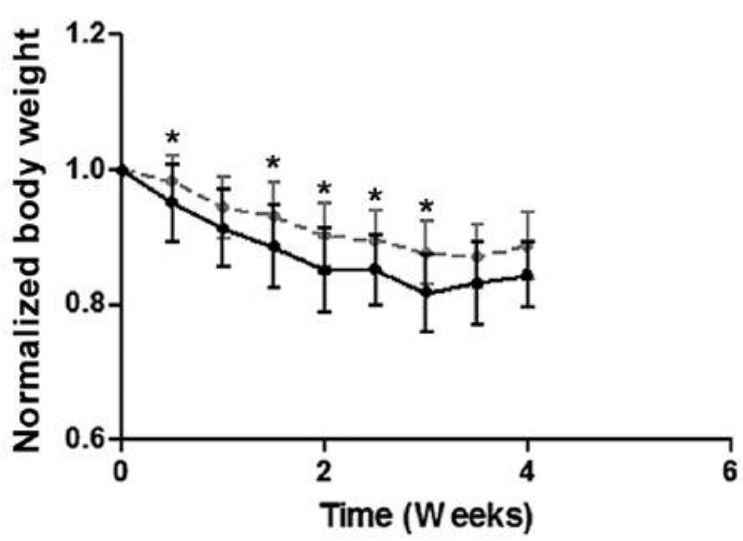

C

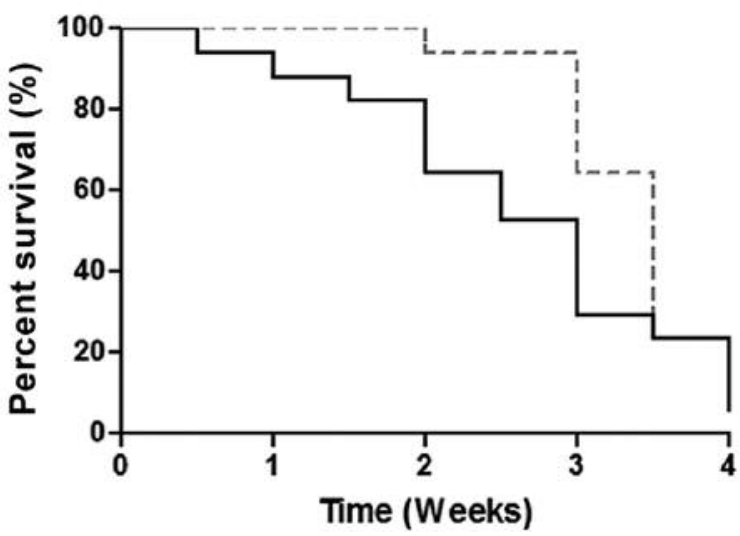

Figure 5. YK-4-279 Treatment of ERG ${ }^{+}$LuCaP 35. LuCaP 35-treated animals $(n=17)$ revealed no overall trends in normalized PSA $(A)$ $(p=0.746), B W(B)(p=0.154)$, or $O S(C)(p=0.171)$ compared to control animals $(n=17)$. PSA and $B W$ results are plotted as normalized mean \pm SEM. $p$-Values pertain to overall treated $v s$. untreated animals. Individual data points marked with $*$ indicate significant difference between control and treated animals at that time point. Gray hatched line $=$ vehicle control, continous black line: YK-4-279 treated .
A

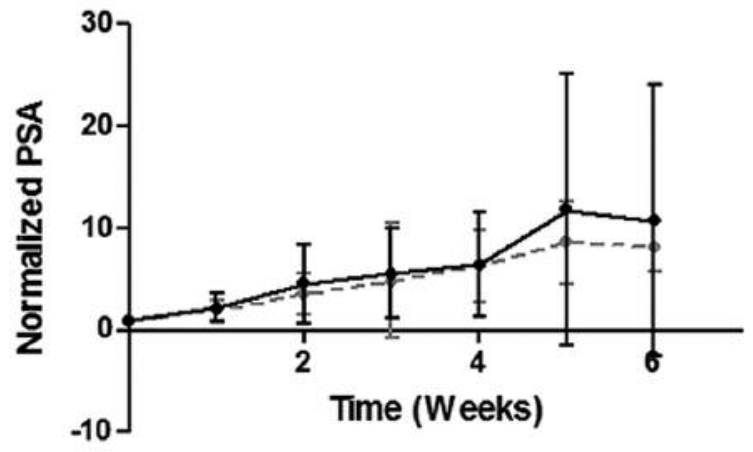

B
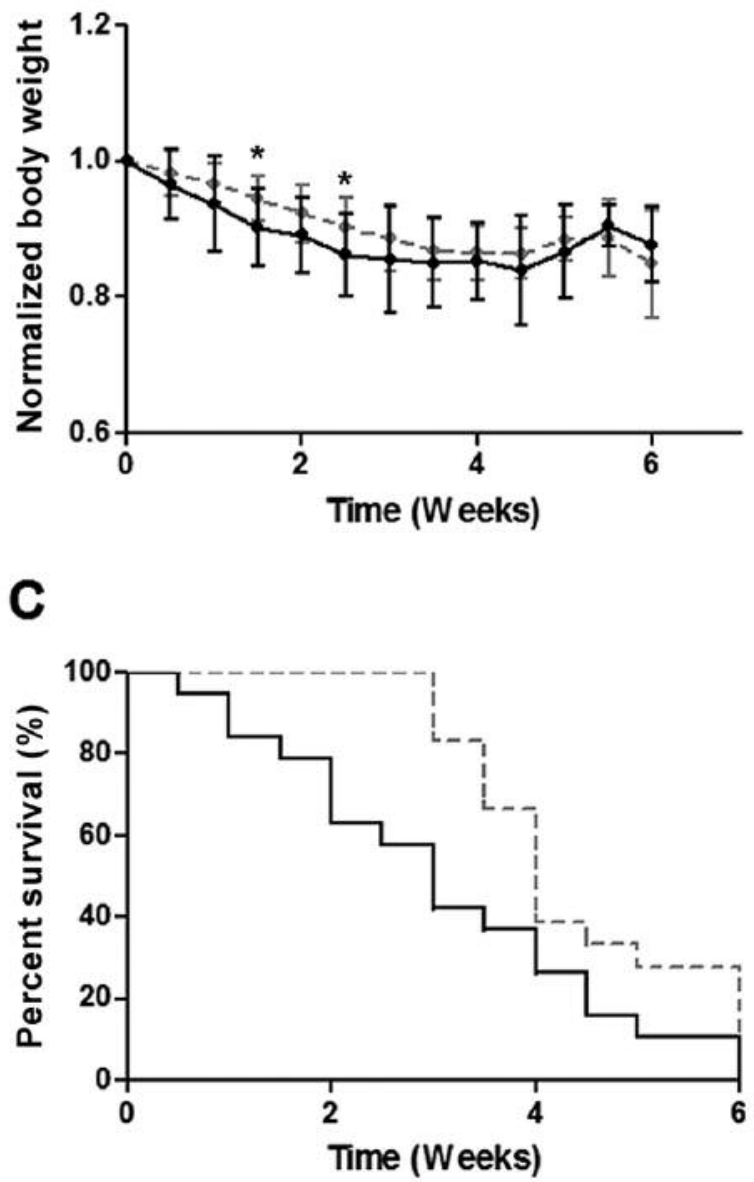

Figure 6. YK-4-279 Treatment of ERG- $L u C a P 96$ (control). LuCaP 96 treated animals $(n=19)$ revealed no overall trends in normalized PSA (A) $(p=0.565)$, or $B W(B)(p=0.382)$ compared to controls $(n=18)$. OS was significantly shorter in YK-4-279-treated animals by the log-rank test $(C)(p=0.026)$. PSA and BW results are plotted as normalized mean $\pm S E M$. p-Values pertain to overall treated vs. untreated animals. Individual data points marked with *indicate significant difference between control and treated animals at that time point. Gray hatched line=vehicle control, continous black line: YK-4-279 treated . 

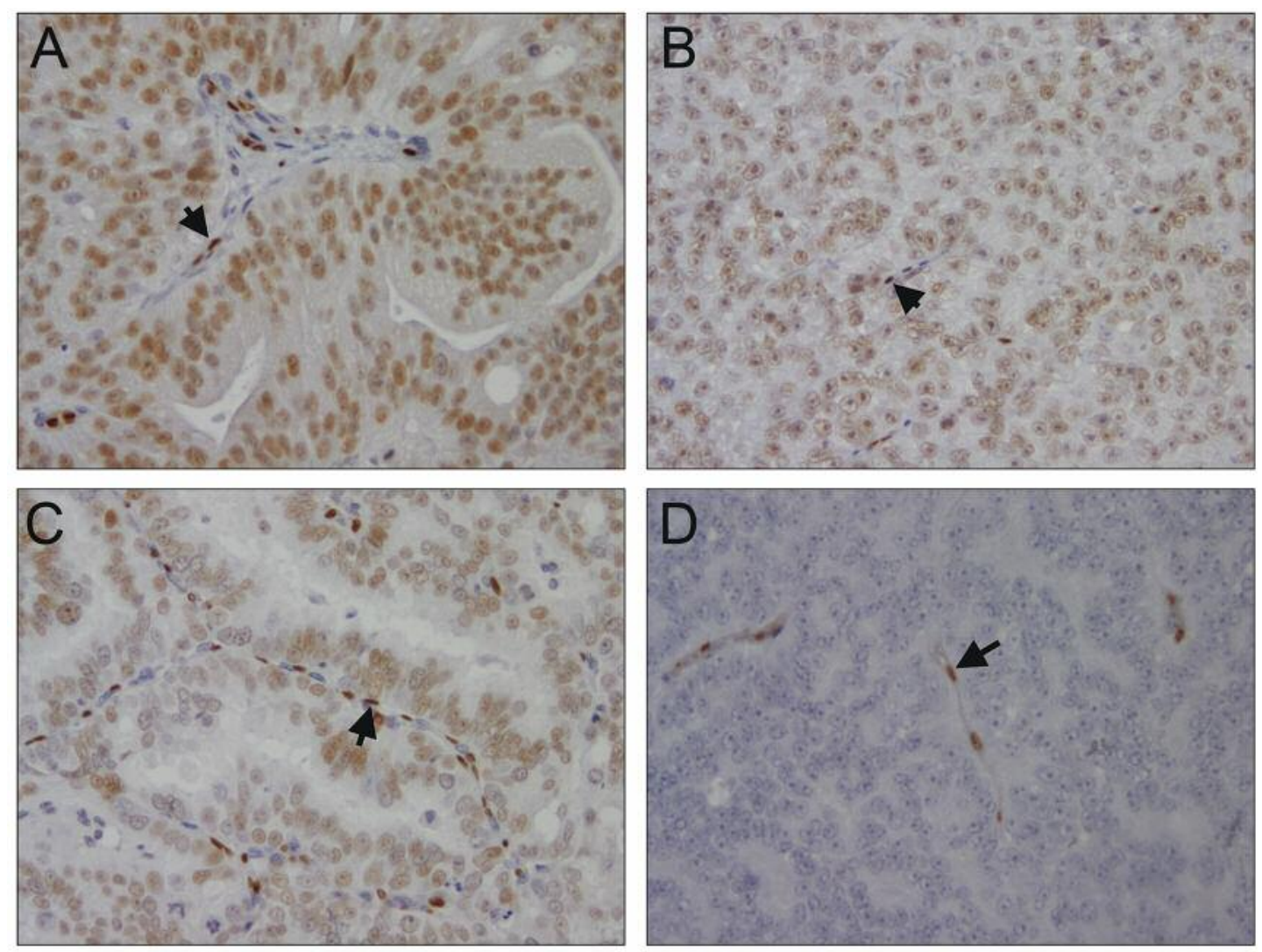

Figure 7. Immunohistochemical analysis of ERG. ERG expression in LuCaP 23.1 (A), LuCaP 35 (B), LuCaP 86.2 (C) and LuCaP 96 (D). Note arrow highlighting ERG expression in endothelial cells. Magnification $\times 200$.

Table II. Antibody information.

\begin{tabular}{lccc}
\hline Protein & Company and Ab cat\# & Antibody type & IHC condition and optimization \\
\hline ERG & Abcam-ab92513 & Rabbit polyclonal & $1: 100$ citrate pH6, 30 min pressure cooker \\
Caspase 3/Cleaved & Cell signaling-9661 & Rabbit polyclonal & $1: 100$ citrate pH6,30 min pressure cooker \\
CD34 & Abcam-ab8158 & Rat monoclonal & $1: 160$ citrate pH6, 30 min pressure cooker \\
ZEB & Sigma-HPA 027524 & Rabbit polyclonal & $1: 100$ citrate pH6, 30 min pressure cooker \\
TWIST & Santa Cruz-Sc15393 & Rabbit polyclonal & $1: 66$ citrate pH6, 30 min pressure cooker \\
\hline
\end{tabular}

\section{Results}

YK-4-279 elicits differential effects on ERG ${ }^{+} P D X$. The $\mathrm{ERG}^{+}$ LuCaP lines for the current study encompass a range of relative ERG expression levels including low (35), medium (23.1) and high expressors (86.2) based on transcript levels (Figure 1). Three $\mathrm{ERG}^{+}\left(23.1,86.2\right.$ and 35) and one ERG ${ }^{-}$PDX (96) were treated with YK-4-279 revealing differential effects on TV, PSA, BW and OS. YK-4-279 treatment of animals bearing LuCaP 23.1 tumors significantly decreased TV $(p=0.026)$ (Figure 2A) and serum PSA $(p=0.0229)$. However, there was a significant decrease in $\mathrm{BW}(p=0.0176)$, with no change in OS (Figure 3). A trend towards decreased TV $(p=0.0563)$ (Figure 2B) and serum PSA levels $(p=0.0921)$ was observed in YK-4-279 treated animals bearing LuCaP 86.2 tumors with no change in BW or OS (Figure 4). YK-4-279 had no effect on LuCaP 35 TV, PSA, BW, or OS (Figure 2C; Figure 5). Finally, the YK-4-279 treated animals bearing the ERG- LuCaP 96 tumors displayed no change in TV, PSA, or BW (as expected), yet these animals experienced a statistically significant decrease in OS ( $p=0.0259)$ (Figure 2D; Figure 6). The impact of YK-4-279 treatment on cell death, proliferation, 

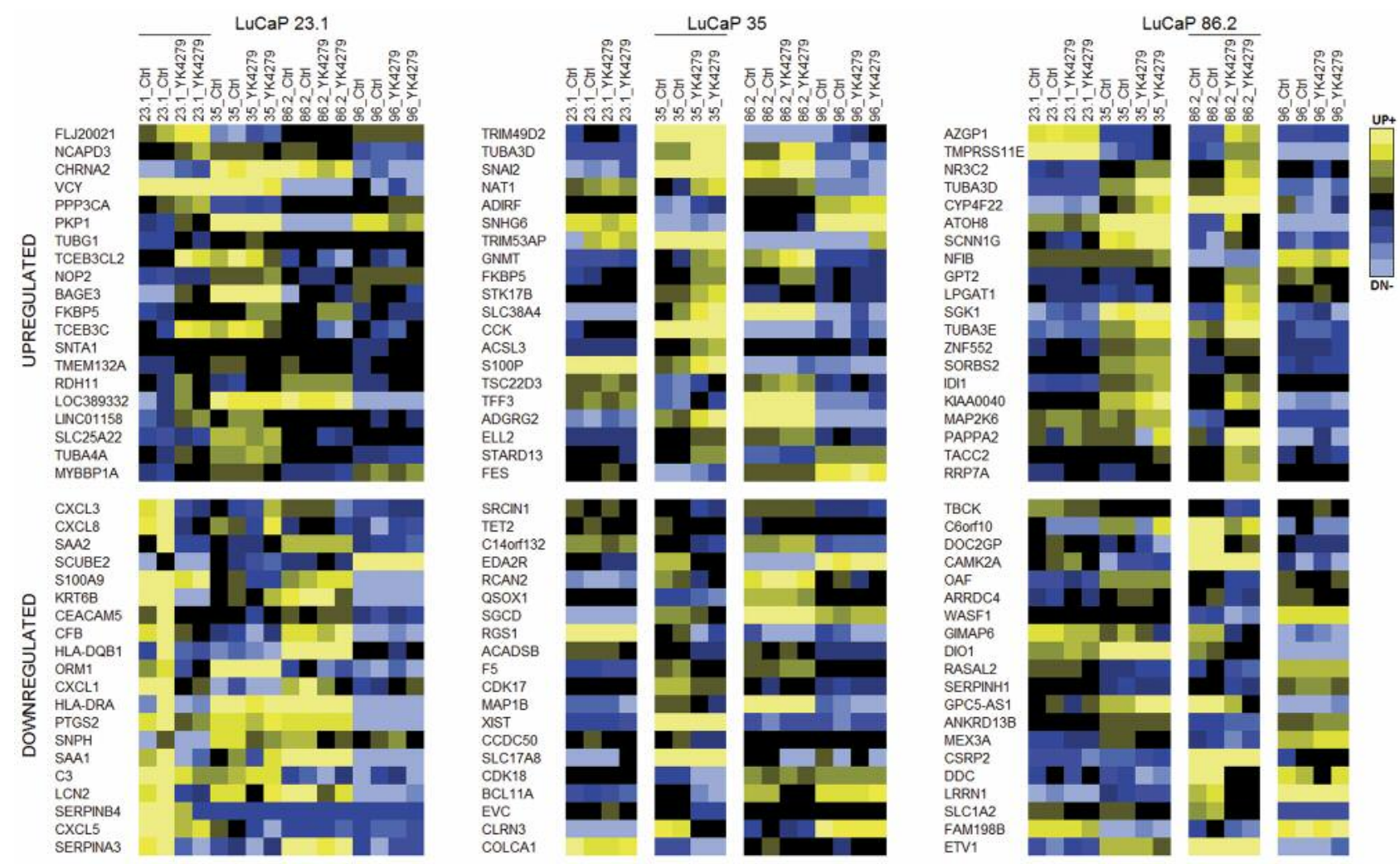

Figure 8. RNA-Seq data of YK-4-279 treated PDX compared to untreated PDX. Tumor RNA was isolated from three ERG expressing PDX LuCaP 23.1, LuCaP 35 and $L u C a P 86.2$ and one $E R G^{-} P D X$ line LuCaP 96. The tumor RNA from YK-4-279 treated and untreated animals on study [2 control, 2 treated from each line ( $n=16)]$ was used for RNA-Seq. The expression of the top 20 upregulated genes and bottom 20 downregulated genes are shown for each of the ERG ${ }^{+}$PDX lines (PDX line of interest is underlined). Ctrl: Vehicle control; YK-4-279: treated.

microvessel density and ERG expression. At the end of the study, $\mathrm{ERG}^{+}$tissues were acquired for histochemical and immunohistochemical analysis. ERG expression was evaluated in all four YK-4-279 treated and vehicle treated PDX lines. All three $\mathrm{ERG}^{+}$PDX lines expressed ERG while LuCaP 96 the $E G^{-}$line did not (Figure 7). No difference in ERG staining was observed between YK-4-279 treated and vehicle treated PDX tumors (LuCaP 23.1 [ $p=0.398]$, LuCaP 35 [ $p=0.688$ ], LuCaP $86.2[p=0.585])$. Initial inspection did not suggest any increase in necrosis between treated and untreated tumors. Cell death, as determined by caspase 3 staining, was no different between the YK-4-279 treated and vehicle treated LuCaP PDX tumors (23.1 [ $p=0.267]$, LuCaP 35 [ $p=0.201]$, LuCaP 86.2 $[p=0.759])$. Tumor cell proliferation, as determined by mitotic index, was significantly different between the YK-4-279 treated and vehicle treated $\mathrm{LuCaP} 23.1(p=0.0038)$. Since ERG is expressed in endothelial cells, microvessel density (CD34) was also assessed in the ERG ${ }^{+}$PDXs, but there was no difference in microvessel density between the YK-4-279 treated and vehicle treated animals ( $\mathrm{LuCaP} 23.1$ [ $p=0.404]$, LuCaP 35 [ $p=0.389]$, LuCaP $86.2[p=0.845])$.
YK-4-279 treatment decreases the expression of ERGassociated genes and increases mineralocorticoid-associated genes. As YK-4-279 is a functional inhibitor of ERG, RNASeq on treated and untreated tumors was used to determine the impact of ERG suppression on downstream gene expression after YK-4-279 treatment (Figure 8). A representative sample of the top 20 up-regulated and bottom 20 down-regulated down genes is shown in Figure 8. As the response to ERG inhibition was different between each of the $\mathrm{ERG}^{+}$PDX lines, each line was assessed separately. Two genes previously shown to be suppressed by ERG in PCa were in the top 20 up-regulated genes in the tumors of the YK-4-279 treated animals, TFF3 and AZGP1 $(18,19)$. No known ERG-associated genes of interest were identified in the 20 down-regulated genes in the PDX tumors post-YK-4-279 treatment with the exception of ETV1 in the LuCaP 86.2 PDX line. This was an unexpected finding as YK-4-279 inhibits ETV1 activity as described (15). ERG has also been associated with epithelial-mesenchymal transition (EMT) $(20,21)$ and while we did identify a decrease in EMT related genes in the LuCaP 23.1 tumors after YK-4-279 treatment $(p=0.01)$, we did not identify a specific EMT- 

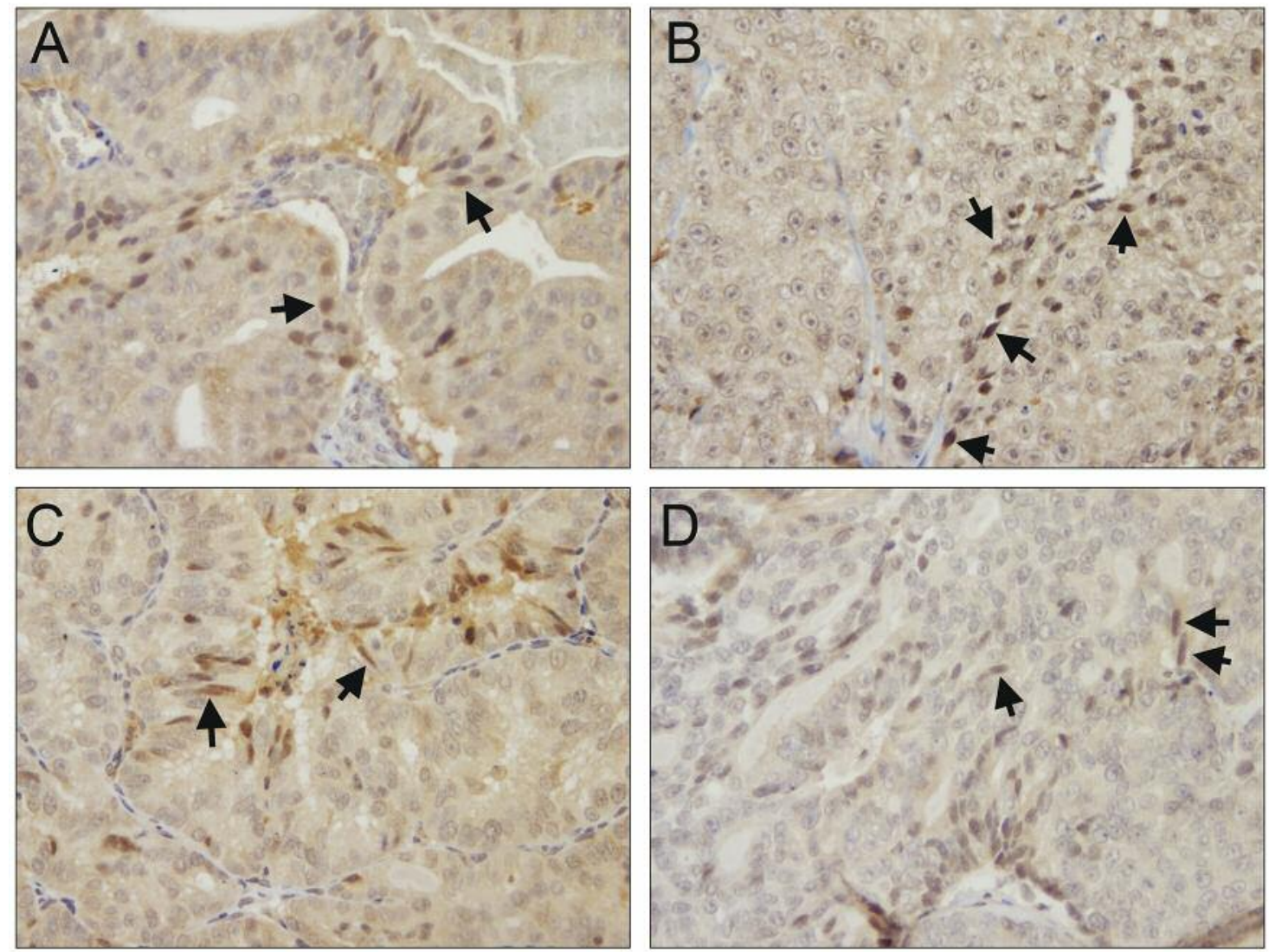

Figure 9. Immunohistochemical analysis of Twist. Twist expression in LuCaP 23.1 (A), LuCaP 35 (B), LuCaP 86.2 (C) and LuCaP 96 (D). Arrows highlight nuclear Twist localization. Magnification $\times 200$.

associated pathway by gene set enrichment analysis in the other lines (GSEA). Additionally, through IHC, tumors were evaluated from YK-4-279-treated and untreated animals for the known EMT transcription factors Twist and Zeb (Figures 9 and 10), but found no difference in protein expression between treated and untreated groups. Further, nuclear staining for these EMT-associated transcription factors was only observed in a subset of cells within each tumor (Figures 9 and 10) (22). Interestingly, in the top 20 genes up-regulated in the PDX tumors after YK-4-279 treatment (Figure 8), a number of genes associated with the mineralocorticoid receptor (MR) were identified. These included the MR itself (NR3C2), SGK1, FKBP5 and TSC22D3 (Figure 8) and each of these genes has been shown to be a direct target of the MR (23) (NR3C2, SGK1, FKBP5, TNS1, TSC22D3 transcript expression is shown in Figure 11). RASL12 is also considered to be a direct target for MR, but it was not present in the RNA-Seq data (23). Steroid receptor activity can also be impacted by microtubule dynamics, which ERG has been suggested to affect (24). An up-regulation of the tubulin genes (TUBA3D, TUBA3E,
TUBA4A, and TUBA4A) and the microtubule interacting protein (TACC2) was observed (25) in the tumors obtained from YK-4-279 treated animals (Figure 8). GSEA demonstrated that the tumors from YK-4-279 treated animals had a gene expression signature similar to a signature upregulated after androgen (R1881) treatment in LNCaP cells (NELSON_RESPONSE_TO_ANDROGEN_UP) $(p<0.001)$. Genes in this group include (FKBP5, SGK1, and AZGP1). Additionally, GSEA demonstrated that enrichment of messages down-regulated after androgen (R1881) treatment in LNCaP cells (NELSON_RESPONSE_TO_ANDROGEN_DN) was significantly associated with messages down-regulated after YK-4-279 treatment $(p<0.001)$.

\section{Discussion}

ERG has been associated with proliferation and metastasis in $\mathrm{PCa}(4,6,20)$. ERG protein is expressed in primary $\mathrm{PCa}$ $(5,6,26)$ and to a lesser extent in metastases $(7,8,27)$. We have argued previously that this difference may indicate 

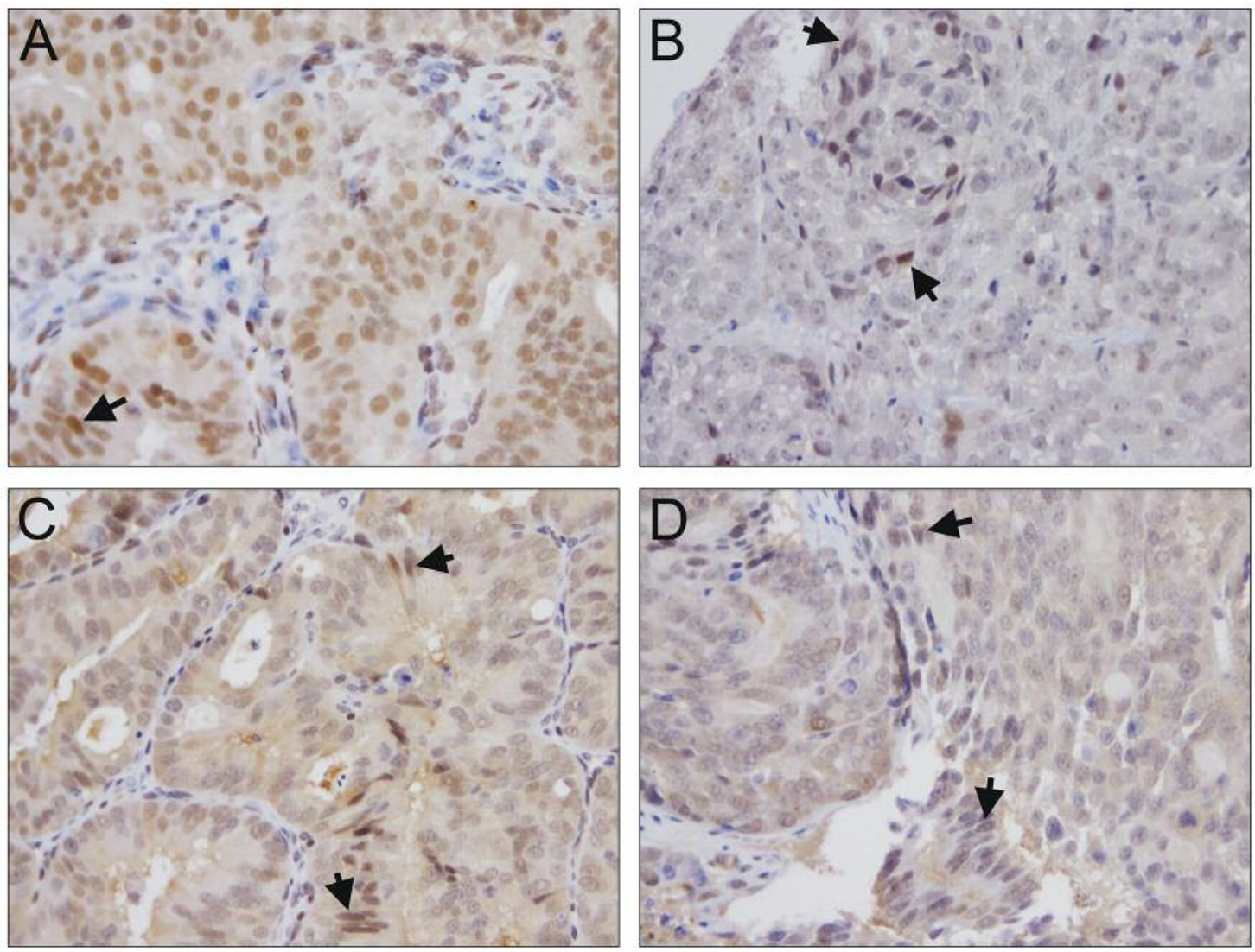

Figure 10. Immunohistochemical analysis of Zeb. Zeb expression in LuCaP 23.1 (A), LuCaP 35 (B), LuCaP 86.2 (C) and LuCaP 96 (D). Arrows highlight nuclear Zeb localization. Magnification $\times 200$.

ERG is important in primary PCa, yet may no longer be required for survival and proliferation in a subgroup of castration-resistant prostate cancer (CRPC) metastases. Thus, these subsets may acquire additional mutations/ rearrangements, promoting proliferation and survival irrespective of ERG expression (8).

YK-4-279 has been shown to decrease tumor growth in ETV1 positive PCa LNCaP tumors (16). However, there are a limited number of $\mathrm{ERG}^{+}$models of PCa. Our hypothesis was that ERG inhibition would impact tumor growth in $\mathrm{PCa}$, with the understanding that PCa is a heterogeneous disease and different tumor phenotypes will display different responses to treatment. To determine the translational application of anti-ERG therapy in PCa, we identified and treated $3 \mathrm{LuCaP}$ PDX lines that expressed ERG with YK-4-279.

We found that the androgen-sensitive LuCaP 23.1 PCa PDX responded to YK-4-279 with significantly decreased tumor volume and serum PSA levels, however the androgen sensitive PDX LuCaP 35 and LuCaP 86.2, which expresses the AR v567es variant, did not significantly respond to treatment (28).

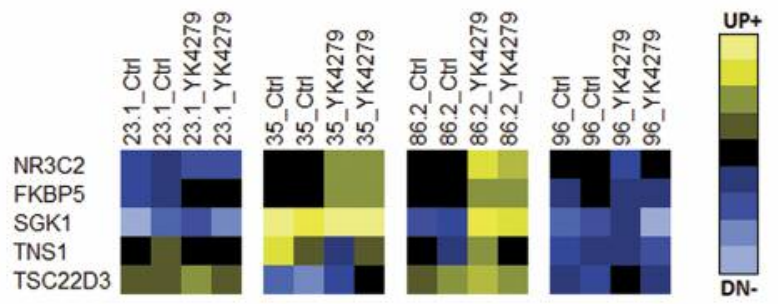

Figure 11. Expression of the mineralocorticoid receptor (NR3C2) and associated genes in YK-4-279 treated PDX compared to untreated PDX. RNA was isolated from tumors from YK-4-279 treated and untreated animals on study (2 control, 2 treated from each line $(n=16))$ for RNA-Seq. Three ERG-expressing PDX lines LuCaP 23.1, LuCaP 35, and LuCaP 86.2 and one ERG-PDX line LuCaP 96. The expression of the mineralocorticoid receptor and four direct target genes regulated by the mineralocorticoid receptor are shown. Ctrl: Vehicle control; YK-4-279: treated.

Taken together, these data suggest a heterogeneous response to YK-4-279 with one PDX line responding, one with a partial response, and a third with no response. Additionally, while tumor volume did not change, animals bearing the $\mathrm{LuCaP} 96$ 
ERG $^{-}$PDX line treated with YK-4-279 similarly to the other $\mathrm{ERG}^{+} \mathrm{LuCaP}$ lines had a decrease in body weight suggesting treatment associated toxicity.

An analysis of proliferation using a mitotic index identified a decrease in proliferative index in LuCaP 23.1 tumors acquired from the animals at the end of the study. We did not observe any difference in apoptosis between the treated and untreated groups. ERG is expressed in endothelial cells and thus ERG inhibition could potentially impact tumor vasculature, however, no change in microvessel density was observed in the PDX models after YK-4-279 treatment.

We used RNA-Seq on tumors from animals on study to determine whether YK-4-279 was impacting gene expression downstream of ERG. Initially, we identified two ERG suppressed genes that were up-regulated after YK-4279 treatment and then focused on known and novel pathways that appeared to be altered in tumors after ERG inhibition by YK-4-279. As mentioned above, ERG has been associated with EMT $(20,21)$ and proliferation (4) yet, we found no proliferation-associated pathways as being differentially regulated in the tumors of treated and untreated animals. Additionally, while the expression of a number of EMT associated genes was changed in the tumors during treatment, no distinct EMT-associated pathways were altered at the gene expression level or by IHC analysis.

One interesting finding by RNA-Seq, was an increase in expression of tubulin proteins and TACC2, a micro-tubule interacting protein (25). ERG has been shown to promote taxane resistance in CRPC (24), however, whether this resistance to taxanes in $\mathrm{ERG}^{+} \mathrm{PCa}$ is related to the regulation of tubulin remains to be seen.

Another interesting finding was the increase in the mineralocorticoid receptor (MR) and its direct target genes after ERG inhibition by YK-4-279. The increase in MR and MR-associated proteins, specifically FKBP5, suggests that MR activity is increased in tumors of animals treated with YK-4-279 (23). However, even though it is a direct target of the MR, FKBP5 generally attenuates MR action, but increases the activity of the androgen receptor (29). The possible action of FKBP5 in promoting AR action is supported by the GSEA analyses showing enrichment of messages up-regulated after androgen (R1881) treatment in LNCaP cells, in response to YK-4-279 treatment.

Our results demonstrated that while there was treatmentassociated toxicity, inhibiting ERG activity using YK-4-279 significantly blocked tumor growth of the LuCaP 23.1 PDX. However, it did not significantly impact LuCaP 35 and LuCaP 86.2 PDX tumor growth. Expression of MRassociated genes and tubulin were increased post-YK-4-279 treatment in these PDX models. Based on these data, we hypothesize that ERG inhibition may represent a potential therapy for some PCa patients with $\mathrm{ERG}^{+}$disease. Followup studies using small- molecule inhibition of ERG, with improved toxicity profiles, are needed to better understand the full potential of targeting ERG in PCa and what potential mechanisms of resistance exist to prevent efficacy of this therapeutic intervention.

\section{Acknowledgements}

We would like to acknowledge Michiyo Dalos, Jessica Olson and Daniel Sondheim for assistance with animal studies. This material is the result of work supported by the Department of Defense (W81XWH-12-1-0399) and the Richard M. LUCAS Foundation.

\section{References}

1 Tomlins SA, Rhodes DR, Perner S, Dhanasekaran SM, Mehra R, Sun XW, Varambally S, Cao X, Tchinda J, Kuefer R, Lee C, Montie JE, Shah RB, Pienta KJ, Rubin MA and Chinnaiyan AM: Recurrent fusion of TMPRSS2 and ETS transcription factor genes in prostate cancer. Science 310: 644-648, 2005.

2 Valdes-Mora F and Clark SJ: Prostate cancer epigenetic biomarkers: next-generation technologies. Oncogene 34: 16091618,2015

3 McLaughlin F, Ludbrook VJ, Cox J, von C, I, Brown S and Randi AM: Combined genomic and antisense analysis reveals that the transcription factor Erg is implicated in endothelial cell differentiation. Blood 98: 3332-3339, 2001.

4 Rahim S and Uren A: Emergence of ETS transcription factors as diagnostic tools and therapeutic targets in prostate cancer. Am J Transl Res 5: 254-268, 2013.

5 Nam RK, Sugar L, Yang W, Srivastava S, Klotz LH, Yang LY, Stanimirovic A, Encioiu E, Neill M, Loblaw DA, Trachtenberg J, Narod SA and Seth A: Expression of the TMPRSS2:ERG fusion gene predicts cancer recurrence after surgery for localised prostate cancer. Br J Cancer 97: 1690-1695, 2007.

6 Perner S, Mosquera JM, Demichelis F, Hofer MD, Paris PL, Simko J, Collins C, Bismar TA, Chinnaiyan AM, De Marzo AM and Rubin MA: TMPRSS2-ERG fusion prostate cancer: an early molecular event associated with invasion. Am J Surg Pathol 31: 882-888, 2007.

7 Teng LH, Wang C, Begin LR, Dolph M, Yilmaz A, Trpkov K, Donnelly B and Bismar TA: ERG protein expression and gene rearrangements are present at lower rates in metastatic and locally advanced castration-resistant prostate cancer compared to localized disease. Urology 82: 394-399, 2013.

8 Roudier MP, Winters BR, Coleman I, Lam HM, Zhang X, Coleman R, Chery L, True LD, Higano CS, Montgomery B, Lange PH, Snyder LA, Srivastava S, Corey E, Vessella RL, Nelson PS, Uren A and Morrissey C: Characterizing the molecular features of ERG-positive tumors in primary and castration resistant prostate cancer. Prostate 76: 810-822, 2016.

9 Hagen RM, Adamo P, Karamat S, Oxley J, Aning JJ, Gillatt D, Persad R, Ladomery MR and Rhodes A: Quantitative analysis of ERG expression and its splice isoforms in formalin-fixed, paraffin-embedded prostate cancer samples: association with seminal vesicle invasion and biochemical recurrence. Am J Clin Pathol 142: 533-540, 2014. 
10 Demichelis F, Fall K, Perner S, Andren O, Schmidt F, Setlur SR, Hoshida Y, Mosquera JM, Pawitan Y, Lee C, Adami HO, Mucci LA, Kantoff PW, Andersson SO, Chinnaiyan AM, Johansson JE and Rubin MA: TMPRSS2:ERG gene fusion associated with lethal prostate cancer in a watchful waiting cohort. Oncogene 26: 4596-4599, 2007.

11 Pettersson A, Graff RE, Bauer SR, Pitt MJ, Lis RT, Stack EC, Martin NE, Kunz L, Penney KL, Ligon AH, Suppan C, Flavin R, Sesso HD, Rider JR, Sweeney C, Stampfer MJ, Fiorentino M, Kantoff PW, Sanda MG, Giovannucci EL, Ding EL, Loda M and Mucci LA: The TMPRSS2:ERG rearrangement, ERG expression, and prostate cancer outcomes: a cohort study and meta-analysis. Cancer Epidemiol Biomarkers Prev 21: 1497$1509,2012$.

12 Fine SW, Gopalan A, Leversha MA, Al-Ahmadie HA, Tickoo SK, Zhou Q, Satagopan JM, Scardino PT, Gerald WL and Reuter VE: TMPRSS2-ERG gene fusion is associated with low Gleason scores and not with high-grade morphological features. Mod Pathol 23: 1325-1333, 2010.

13 Font-Tello A, Juanpere N, de MS, Lorenzo M, Lorente JA, Fumado L, Serrano L, Serrano S, Lloreta J and Hernandez S: Association of ERG and TMPRSS2-ERG with grade, stage, and prognosis of prostate cancer is dependent on their expression levels. Prostate 75: 1216-1226, 2015.

14 Erkizan HV, Kong Y, Merchant M, Schlottmann S, BarberRotenberg JS, Yuan L, Abaan OD, Chou TH, Dakshanamurthy S, Brown ML, Uren A and Toretsky JA: A small molecule blocking oncogenic protein EWS-FLI1 interaction with RNA helicase A inhibits growth of Ewing's sarcoma. Nat Med 15: 750-756, 2009.

15 Rahim S, Beauchamp EM, Kong Y, Brown ML, Toretsky JA and Uren A: YK-4-279 inhibits ERG and ETV1 mediated prostate cancer cell invasion. PLoS One 6: e19343, 2011.

16 Rahim S, Minas T, Hong SH, Justvig S, Celik H, Kont YS, Han J, Kallarakal AT, Kong Y, Rudek MA, Brown ML, Kallakury B, Toretsky JA and Uren A: A small molecule inhibitor of ETV1, YK-4-279, prevents prostate cancer growth and metastasis in a mouse xenograft model. PLoS One 9: e114260, 2014.

17 Chou J, Fitzgibbon MP, Mortales CL, Towlerton AM, Upton MP, Yeung RS, McIntosh MW and Warren EH: Phenotypic and transcriptional fidelity of patient-derived colon cancer xenografts in immune-deficient mice. PLoS One 8: e79874, 2013.

18 Rickman DS, Chen YB, Banerjee S, Pan Y, Yu J, Vuong T, Perner S, Lafargue CJ, Mertz KD, Setlur SR, Sircar K, Chinnaiyan AM, Bismar TA, Rubin MA and Demichelis F: ERG cooperates with androgen receptor in regulating trefoil factor 3 in prostate cancer disease progression. Neoplasia 12: 1031-1040, 2010.

19 Burdelski C, Kleinhans S, Kluth M, Hube-Magg C, Minner S, Koop C, Graefen M, Heinzer H, Tsourlakis MC, Wilczak W, Marx A, Sauter G, Wittmer C, Huland H, Simon R, Schlomm T and Steurer S: Reduced AZGP1 expression is an independent predictor of early PSA recurrence and associated with ERGfusion positive and PTEN deleted prostate cancers. Int J Cancer 138: 1199-1206, 2016.
20 Leshem O, Madar S, Kogan-Sakin I, Kamer I, Goldstein I, Brosh R, Cohen Y, Jacob-Hirsch J, Ehrlich M, Ben-Sasson S, Goldfinger N, Loewenthal R, Gazit E, Rotter V and Berger R: TMPRSS2/ERG promotes epithelial to mesenchymal transition through the ZEB1/ZEB2 axis in a prostate cancer model. PLoS One 6: e21650, 2011.

$21 \mathrm{Kim}$ J, Wu L, Zhao JC, Jin HJ and Yu J: TMPRSS2-ERG gene fusions induce prostate tumorigenesis by modulating microRNA miR-200c. Oncogene 33: 5183-5192, 2014.

22 Haider M, Zhang X, Coleman I, Ericson N, True LD, Lam HM, Brown LG, Ketchanji M, Nghiem B, Lakely B, Coleman R, Montgomery B, Lange PH, Roudier M, Higano CS, Bielas JH, Nelson PS, Vessella RL and Morrissey C: Epithelial mesenchymal-like transition occurs in a subset of cells in castration resistant prostate cancer bone metastases. Clin Exp Metastasis 33: 239-248, 2016.

23 Ueda K, Fujiki K, Shirahige K, Gomez-Sanchez CE, Fujita T, Nangaku $M$ and Nagase M: Genome-wide analysis of murine renal distal convoluted tubular cells for the target genes of mineralocorticoid receptor. Biochem Biophys Res Commun 445: 132-137, 2014

24 Galletti G, Matov A, Beltran H, Fontugne J, Miguel MJ, Cheung C, MacDonald TY, Sung M, O'Toole S, Kench JG, Suk CS, Kimovski D, Tagawa ST, Nanus DM, Rubin MA, Horvath LG, Giannakakou P and Rickman DS: ERG induces taxane resistance in castration-resistant prostate cancer. Nat Commun 5: 5548, 2014.

25 Takayama K, Horie-Inoue K, Suzuki T, Urano T, Ikeda K, Fujimura T, Takahashi S, Homma Y, Ouchi Y and Inoue S: TACC2 is an androgen-responsive cell cycle regulator promoting androgen-mediated and castration-resistant growth of prostate cancer. Mol Endocrinol 26: 748-761, 2012.

26 Darnel AD, Lafargue CJ, Vollmer RT, Corcos J and Bismar TA: TMPRSS2-ERG fusion is frequently observed in Gleason pattern 3 prostate cancer in a Canadian cohort. Cancer Biol Ther 8: 125130, 2009.

27 Scheble VJ, Scharf G, Braun M, Ruiz C, Sturm S, Petersen K, Beschorner R, Bachmann A, Zellweger T, Fend F, Kristiansen G, Bubendorf L, Wernert N, Shaikhibrahim Z and Perner S: ERG rearrangement in local recurrences compared to distant metastases of castration-resistant prostate cancer. Virchows Arch 461: 157-162, 2012.

28 Li Y, Hwang TH, Oseth LA, Hauge A, Vessella RL, Schmechel SC, Hirsch B, Beckman KB, Silverstein KA and Dehm SM: AR intragenic deletions linked to androgen receptor splice variant expression and activity in models of prostate cancer progression. Oncogene 31: 4759-4767, 2012.

29 Jaaskelainen T, Makkonen H and Palvimo JJ: Steroid upregulation of FKBP51 and its role in hormone signaling. Curr Opin Pharmacol 11: 326-331, 2011.

Received April 25, 2017

Revised May 13, 2017

Accepted May 17, 2017 